\title{
High glucose induces formation of tau hyperphosphorylation via Cav-1-mTOR pathway: A potential molecular mechanism for diabetes-induced cognitive dysfunction
}

\author{
Jing Wu ${ }^{1}$, Shan-Lei Zhou ${ }^{1}$, Lin-Hua $\mathrm{Pi}^{1}$, Xia-Jie Shi ${ }^{1}$, Ling-Ran Ma ${ }^{2}$, Zi Chen ${ }^{1}$, Min-Li \\ $\mathbf{Q u}^{1}$, Xin $\mathrm{Li}^{2}$, Sheng-Dan $\mathrm{Nie}^{3}$, Duan-Fang Liao ${ }^{4}$, Jin-Jing Pei, ${ }^{5,6,7}$ and Shan Wang ${ }^{1,2}$ \\ ${ }^{1}$ Department of Endocrinology, Xiang-Ya Hospital, Central South University, Changsha, Hunan, China \\ ${ }^{2}$ Department of Pharmaceutical Engineering, College of Chemistry and Chemical Engineering, Central South University, \\ Changsha, Hunan, China \\ ${ }^{3}$ Institute of Clinical Medicine, People's Hospital of Hunan Province, The First Affiliated Hospital of Hunan Normal University, \\ Changsha, Hunan, China \\ ${ }^{4}$ Division of Stem Cell Regulation and Application, School of Pharmacy, Hunan University of Traditional Chinese Medicine, \\ Changsha, Hunan, China \\ ${ }^{5}$ KI-Alzheimer's Disease Research Center, Karolinska Institutet, Novum, Stockholm, Sweden \\ ${ }^{6}$ Department of Neurology, Xuan Wu Hospital, Capital Medical University, Xicheng, Beijing, China \\ ${ }^{7}$ Center of Alzheimer's Disease, Beijing Institute for Brain Disorders, Beijing, China \\ Correspondence to: Shan Wang, email: wangshancsu0717@163.com \\ Jing Wu, email: wujing0731@163.com
}

Keywords: diabetes mellitus, cognitive dysfunction, caveolin-1, tau hyperphosphorylation, mTOR

Received: February 20, 2017 Accepted: April 07, $2017 \quad$ Published: April 19, 2017

Copyright: Wu et al. This is an open-access article distributed under the terms of the Creative Commons Attribution License 3.0 (CC BY 3.0), which permits unrestricted use, distribution, and reproduction in any medium, provided the original author and source are credited.

\section{ABSTRACT}

The abnormally hyperphosphorylated tau is thought to be implicated in diabetesassociated cognitive deficits. The role of mammalian target of rapamycin (mTOR) / S6 kinase (S6K) signalling in the formation of tau hyperphosphorylation has been previously studied. Caveolin-1 (Cav-1), the essential structure protein of caveolae, promotes neuronal survival and growth, and inhibits glucose metabolism. In this study, we aimed to investigate the role of Cav-1 in the formation of tau hyperphosphorylation under chronic hyperglycemic condition (HGC). Diabetic rats were induced by streptozotocin (STZ). Primary hippocampal neurons with or without molecular intervention such as the transient over-expression or knock-down were subjected to HGC. The obtained experimental samples were analyzed by real time quantitative RT-PCR, Western blot, immunofluorescence or immunohistochemisty. We found: 1) that a chronic HGC directly decreases Cav-1 expression, increases tau phosphorylation and activates mTOR/ S6K signalling in the brain neurons of diabetic rats, 2) that overexpression of Cav-1 attenuates tau hyperphosphorylation induced by chronic HGC in primary hippocampal neurons, whereas down-regulation of Cav-1 using Cav-1 siRNA dramatically worsens tau hyperphosphorylation via mTOR/S6K signalling pathway, and 3) that the downregulation of Cav-1 induced by HGC is independent of mTOR signalling. Our results suggest that tau hyperphosphorylation and the sustained over-activated mTOR signalling under hyperglycemia may be due to the suppression of Cav-1. Therefore, Cav-1 is a potential therapeutic target for diabetes-induced cognitive dysfunction.

\section{INTRODUCTION}

Diabetes mellitus (DM), characterized by hyperglycemia, has adverse effects on the brain of affected subjects, especially on the hippocampus, a brain area particularly susceptible to harmful stimuli [1]. A large number of epidemiological findings have suggested that DM patients are at risk for developing cognitive decline 
$[2,3]$. Experimental studies have found significant cognitive deficits in streptozotocin (STZ)-induced hyperglycemic diabetic rats [4].

Tau is a neuron-enriched phospho-protein, is one of the major microtubule-associated proteins. It normally binds to microtubules, promotes tubulin assembly into microtubules and stabilizes microtubules in neurons [5]. When tau is abnormally hyperphosphorylated, it detaches from microtubules and aggregates into paired helical filaments (PHFs) in neurofibrillary tangles (NFTs), a characteristic neuropathological hallmarker in the brains of patients diagnosed as tauopathies, of which Alzheimer disease (AD) is the most common form [6]. It has been reported that the severity of tau-pathologies strongly correlates with cognitive impairment in $\mathrm{AD}$ patients [7]. Similar to AD, DM is also considered as tauopathy-associated disease based on the formation of tau hyperphosphorylation in DM brains [8-10].Alonso et al. have demonstrated that transfected PC 12 cells with pseudophosphorylated tau caused neurodegeneration [11]. Di $\mathrm{J}$ et al. created an inducible pseudophosphorylated tau mouse model to study the effect of conformationally modified tau in vivo [12], although rodent tau does not naturally form PHFs or NFTs [8]. They demonstrated that abnormally hyperphosphorylated tau is sufficient to induce neurodegeneration that results in cognitive deficits [12]. Inhibition of the formation of tau hyperphosphorylation could reverse the development of cognitive dysfunction in DM [13].

The ribosomal proteinS6 kinase ( $\mathrm{S} 6 \mathrm{~K})$ is one of the major downstream targets of mammalian target of rapamycin (mTOR), its phosphorylation level is a wellknown parameter to evaluate mTOR activity [14]. mTOR/ S6K signalling is required for glucose metabolism and memory formation [15-20]. However, the over-activated mTOR/S6K signalling is thought to be implicated in cognitive dysfunction [21]. The role of mTOR/S6K signalling in the formation of tau hyperphosphorylation has been previously studied in several model systems such as human SH-SY5Y neuroblastoma cells and mouse neuroblastoma 2a (N2a) cells, primary cortical neurons and metabolically active brain slices [22-27]. The abnormal upregulation of mTOR and S6K was found to be associated with accumulation of hyperphosphorylated tau in AD brain $[26,28]$. Inhibition of mTOR with rapamycin improved learning and memory, and reduced tau pathology in a transgenic mouse model of AD [29]. Also, rapamycin treatment improved locomotor and exploratory activity, and prevented neurodenegeration and tau phosphorylation in senescence-accelerated OXYS rats [30]. In our recent study, we found that $\mathrm{mTOR} / \mathrm{S} 6 \mathrm{~K}$ signalling is over-activated in the brains of diabetic mice and that inhibition of mTOR signalling with rapamycin alleviates the phosphorylation level of hyperphosphorylated tau and prevents the formation of DM-induced cognitive deficits [31].
Caveolin-1 (Cav-1), a transmembrane scaffolding protein, found within membrane/lipid rafts, is specifically abundant in neurons in central nervous system [32]. It was reported that neuron-targeted overexpression of Cav-1 enhances functional neuronal membrane/lipid rafts, and improves hippocampus-dependent learning and memory $[33,34]$. An accelerated tau-related neurodegeneration and a number of motor and behavioral abnormalities were found in Cav-1 knockout mice [32, 35]. Several studies have demonstrated that Cav-1 negatively regulates mTOR signalling in different cells [36-39], the later one is required for the formation of tau hyperphosphorylation $[22,23]$. Thus, we speculate that Cav-1-mTOR/S6K signalling may be involved in the formation of tau hyperphosphorylation. Also, the expression of Cav-1 could be down-regulated in hyperglycemic condition (HGC) in several cells, such as mesenteric vascular smooth muscle cells, lens epithelial cells and monocytes [40-42]. In the hippocampi of STZ-induced diabetic rats that mimic HGC, the down-regulation of Cav-1 was demonstrated by Western blotting [43]. However, how Cav-1 is involved in the formation of tau hyperphosphorylation in HGC is not clear.

Given that DM patients have a higher risk of developing $\mathrm{AD}$ in the process of ageing as compared to non-DM control subjects [44], and that neurodenegeration mediated by abnormal tau is implicated in both $\mathrm{AD}$ and DM-related cognitive dysfunction [45], it is imperative to elucidate the potential molecular mechanisms underlying the DM induced-neurodegeneration so that to provide appropriate clinical interventions with aims to decrease or remove the risk of developing $\mathrm{AD}$ in this $\mathrm{DM}$ population. In this study we have mimicked a major biochemical change observed in DM patients: chronic hyperglycemia, in primary hippocampal neurons and STZ-induced diabetic rat model, and have investigated whether or not Cav-1 is involved in the formation of tau hyperphosphorylation in HGC. Our major findings are: 1) that STZ-induced persistent hyperglycemia is associated with cognitive dysfunction, 2) that the up-regulated mTOR/S6K signalling causes the formation of tau hyperphosphorylation in hippocampal neurons, 3) that decreased Cav-1 expression contributes to the formation of tau hyperphosphorylation in $\mathrm{HGC}$, and 4) that mTOR/S6K signalling is required for Cav-1-regulated tau hyperphosphorylation.

\section{RESULTS}

\section{Correlation of STZ-induced persistent hyperglycemia and cognitive dysfunction}

A sharp increase of FBG level was observed from the 3rd day of STZ injection, and the increased FBG level was remained at the 12 th week of STZ injection as compared to the control group (Table 1), suggesting 


\begin{tabular}{|c|c|c|}
\hline Groups & Control group & STZ group \\
\hline Number of rats & 10 & 10 \\
\hline FBG 3 days (mM) & $5.13 \pm 0.93$ & $26.13 \pm 4.12 * *$ \\
\hline FBG 12 weeks (mM) & $5.43 \pm 0.62$ & $19.16 \pm 1.33 * *$ \\
\hline Body weight 12 weeks (g) & $375.28 \pm 30.33$ & $280.16 \pm 28.91^{*}$ \\
\hline
\end{tabular}

STZ and FBG are abbreviations of streptozotocin and fasting blood glucose respectively. All results are presented as mean \pm s.e.m. $* p<0.05$ vs control group; $* * p<0.01$ vs control group.

that a persistent hyperglycemia is induced by STZ. In the training, the averaged escape latency of both experimental and control groups decreased in correlation with the progression of the number of training days, and it took more time for the diabetic rats to get on the platform on training day 2 , day 3 and day 4 as compared with the control rats (panel Figure 1A). It suggests that a deficit in spatial learning ability is present in diabetic rats. In the tests, diabetic rats showed a significant increase in the escape latency as compared to the controls (panel Figure 1B). In the probe trial, the time spent in the target quadrant with the hidden platform was decreased in diabetic rats compared with the controls (Panel Figure 1C). No significant difference in the swimming velocity was observed between the diabetic and control groups (panel Figure 1D). The ability to escape from a visible platform was also evaluated, and no differences in vision and basal motivation were found in the diabetic and control groups (data not shown). Our results indicated that the acquisition of spatial reference learning and the retrieval of spatial memory are impaired in STZ-induced diabetic rats.

\section{The up-regulated mTOR/S6K signalling causes the formation of tau hyperphosphorylation in hippocampal neurons}

The levels of the p-tau at both Thr231 and Ser396/404 (PHF-1) epitopes but not total tau showed a sharp and significant increase in the hippocampi of diabetic rats as compared to controls (panel Figure 2A). The higher levels of p-mTOR and p-S6K but not the total levels of them

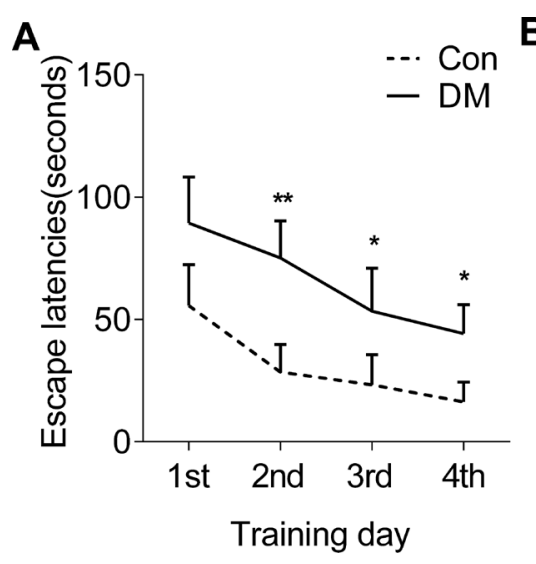

B
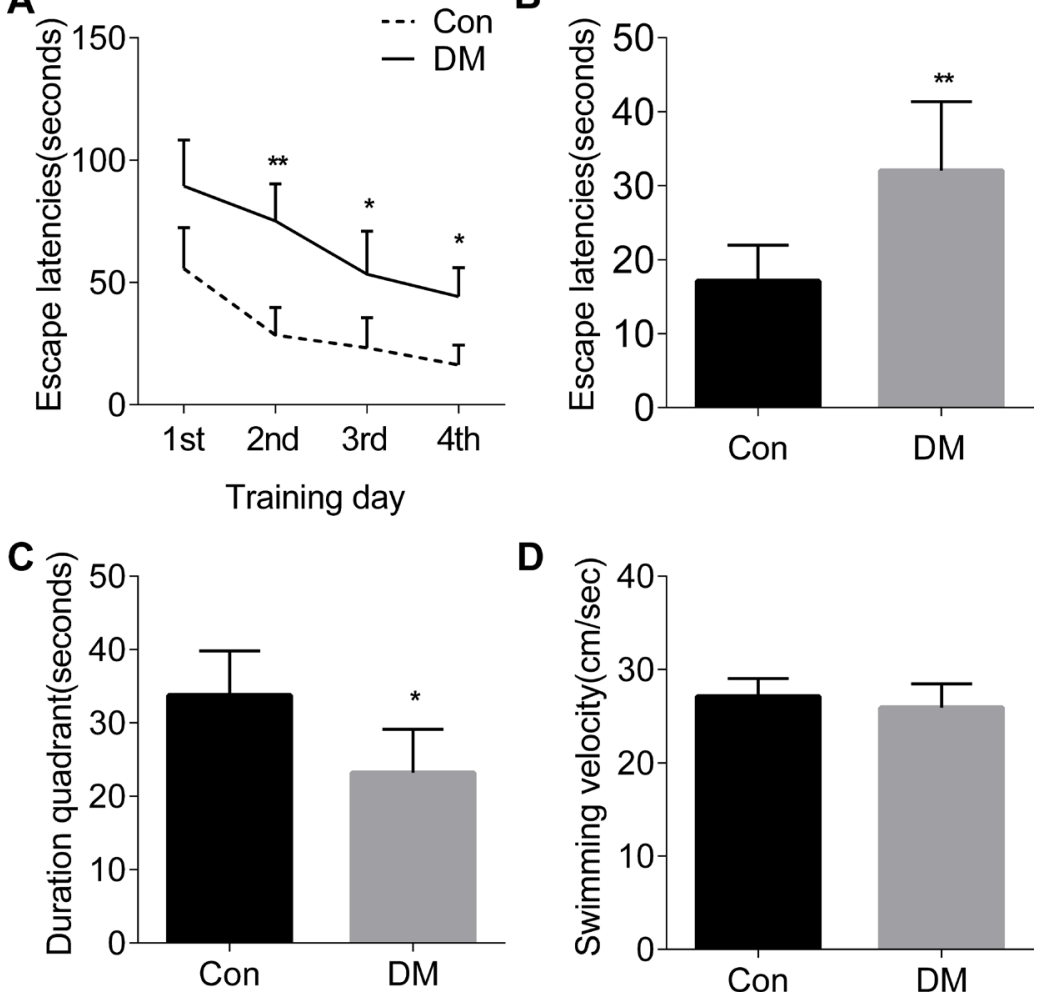

Figure 1: The spatial learning and memory deficits in diabetic rats. (A) The rat learning acquisition. (B) The spatial learning acquistition. (C) The spatial memory retrieval. (D) The swimming velocity. Con, normal control rats; DM, diabetic rats. $* p<0.05$, $* * p<0.01$ vs Con. Error bars represent s.e.m. 
were also observed in the hippocampi of diabetic rats as compared to the control rats (panel Figure 2A).

The viability of the primary hippocampal neurons assessed by the CCK-8 assay (panel Figure 2B) showed no significant change between the chronic HGC group (long-term exposure to $50 \mathrm{mM}$ glucose for 6 days) and the osmotic control (25 mM mannitol plus $25 \mathrm{mM}$ glucose). The levels of p-tau at both Thr231 and PHF-1 epitopes, p-mTOR and p-S6K were remarkably increased in the HGC group as compared with the control, while levels of total tau, mTOR and S6K remained unchanged (panel Figure 2C), which was reversed by the pretreatment of primary hippocampal neurons with $200 \mathrm{nM}$ rapamycin (panel Figure 2C). However, no dramatic morphological changes were observed in the HGC group as compared to the control by immunofluorescence using anti-neurospecific class $3 \beta$-tubulin and anti-Syn antibodies as neuronal biomarkers (panel Figure 2D).

\section{Decreased Cav-1 expression contributes to the formation of tau hyperphosphorylation under HGC}

As shown in panel Figure 3A, faint immunoreactivities of Cav-1 were observed in the CA1 pyramidal neurons of the hippocampus in the diabetic brains, as compared to the control. The protein expression level of Cav-1 by Western blotting was significantly decreased in the hippocampi of diabetic rats (panel Figure 3B).

The mRNA expression of Cav-1 measured by Real time PCR showed a dramatic decrease $(62.5 \%)$ in $50 \mathrm{mM}$ glucose treated group as compared with control (panel Figure 3C). The protein expression of Cav-1 by Western blots demonstrated $51 \%$ reduction in experimental group as compared with control (panel Figure 3D). However, no change was observed in mannitol-treated osmotic control group (panel Figure 3C-3D). By immunofluorescence staining, decreased Cav-1 immunosignals were observed in HG-treated group compared with the control group (panel Figure 3E).

The primary hippocampal neurons transfected with Cav-1 siRNA generated a $77 \%$ and $56 \%$ reduction for mRNA and protein level, respectively, in the silenced group as compared with the control, whereas scrambled siRNA (SC-siRNA) showed no effect on both protein and mRNA levels of the Cav-1 (Supplementary Figure $1 \mathrm{~A}-1 \mathrm{~B})$. As illustrated in panel Figure 3F, in normal condition, transfection of the primary hippocampal neurons with Cav-1 siRNA induced a slight but significant increased levels of p-tau at Thr 231 and PHF-1 epitopes
A

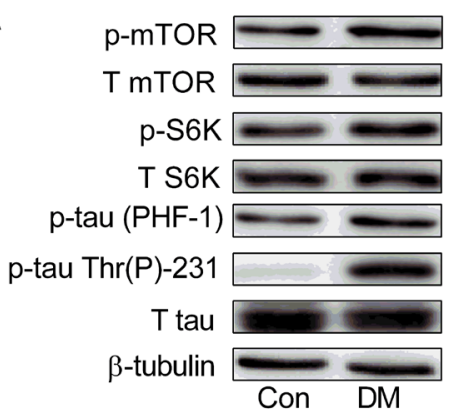

C

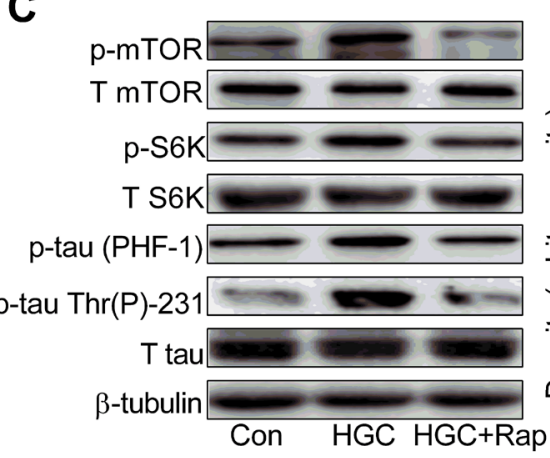

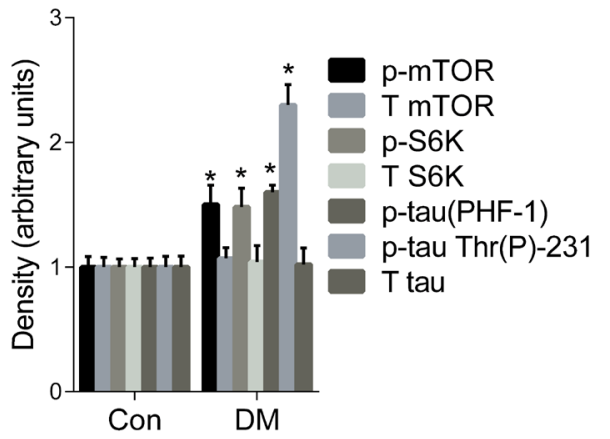
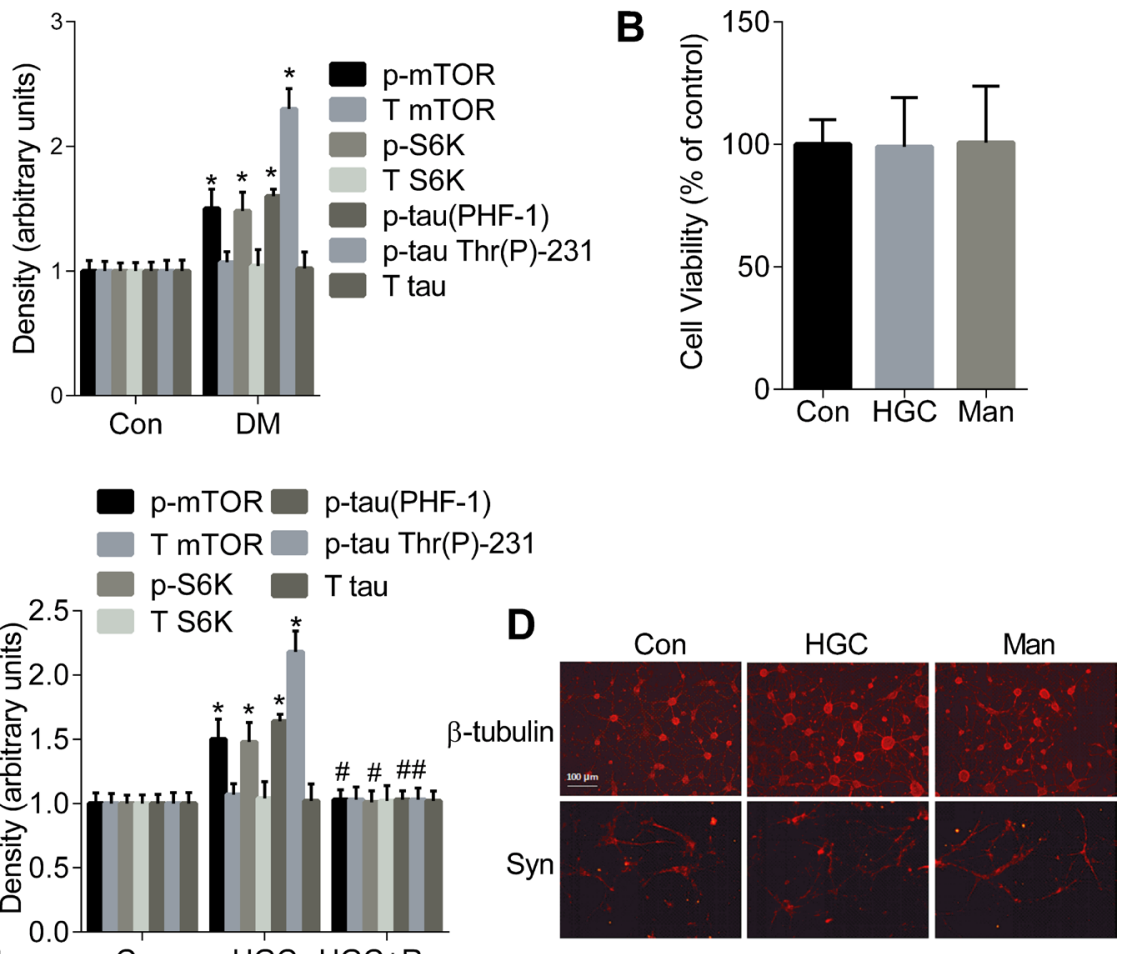

Figure 2: The up-regulated mTOR/S6K signalling causes the formation of tau hyperphosphorylation. (A) Western blot analysis showed the expression levels of tau phosphorylation and the phosphorylation of mTOR and S6K in the hippocampi of control and diabetic rats brains. (B) Cell viability was assessed by CCK-8 assay. (C) Western blot showed the levels of tau phosphorylation and the phosphorylation of mTOR and S6K in primary hippocampal neurons exposed to $25 \mathrm{mM}$ glucose (Con), $50 \mathrm{mM}$ glucose (HGC) or $50 \mathrm{mM}$ glucose and $200 \mathrm{nM}$ rapamycin (HGC + Rap) for 6 days. (D) The morphology of hippocampal neurons was analyzed by immunofluorescence using anti- $\beta$-III tubulin and anti-Syn antibodies. ${ }^{*} p<0.05$ vs Con; ${ }^{*} p<0.05$ vs HGC. Error bars represent s.e.m. 
as compared with the SC-siRNA group. In HGC, Cav1 silenced group showed aggravated levels of p-tau at Thr 231 and Ser $396 / 404$ epitopes by $26.5 \%$ and $24.4 \%$ respectively.

Furthermore, as shown in panel Figure 3G, infection of primary hippocampal neurons with adenovirus encoding Cav-1 showed a dramatic reduction of the levels of p-tau at Thr 231 and PHF-1 epitopes induced by HGC as compared to the control. The over-expression of the Cav-1 was confirmed by both Real time PCR and Western blot methods (Supplementary Figure 2A-2B). These results suggest that Cav-1 is sufficient to reverse HGC-induced tau hyperphosphorylation in hippocampal neurons.

\section{mTOR/S6K signalling is required for Cav-1- regulated hyperphosphorylation of tau}

As shown in panel Figure 4, primary hippocampal neurons transfected with Cav-1 siRNA showed much higher levels of p-mTOR and p-S6K in HGC. In contrast, primary hippocampal neurons with Cav-1 overexpression showed a lower level of p-mTOR and p-S6K compared with the HGC group (panel Figure 4A). When neurons were pretreated with mTOR inhibitor rapamycin, tau hyperphosphorylation induced by $\mathrm{HG}$ and/or Cav1 knockdown disappeared (panel Figure 4B). These results suggested that Cav-1 negatively regulates the activation of $\mathrm{mTOR} / \mathrm{S} 6 \mathrm{~K}$ signalling pathway, which is required for $\mathrm{HG}$ and/or Cav-1 knockdown-induced tau hyperphosphorylation. Furthermore, as shown in panels Figure 4C-4D, the levels of both Cav-1 mRNA and protein were not affected by rapamycin treatment compared with the HGC group, suggesting the expression of Cav-1 is not regulated by mTOR signalling (Figure 4C-4D).

\section{DISCUSSION}

Chronic hyperglycemia is thought to reduce the function efficiency of brain networks in DM patients, leading to cognitive impairment [46]. In AD APP/PS1 transgenic mice, chronic hyperglycemia was reported to worsen the neuropathological lesion, suggesting that glycemic control may be beneficial for decreasing the incidence of $\mathrm{AD}$ in diabetic patients [47]. In the diabetic rats in the present study, STZ-induced persistent hyperglycemia is associated with cognitive dysfunction. The positive correlation between persistent hyperglycemia and cognitive dysfunction was also found in STZinduced diabetic mice and spontaneously diabetic GotoKakizaki (GK) rats $[31,48]$. Several DM hyperglycemia ameliorating drugs such as the peroxisome proliferatoractivated receptor gamma (PPAR $\gamma$ ) agonist, glucagon-like peptide-1 (GLP-1) and dipeptidylpeptidase-4 inhibitor were reported to improve the cognitive deficits in DM patients [49-51]. These results suggested that persistent hyperglycemia maybe one of the primary triggers for the development of cognitive impairment in diabetic patients. Growing evidence has indicated that neurodegeneration mediated by the formation of hyperphosphorylated tau contributes to the diabetesassociated cognitive deficit [52-54]. Although tau aggregation or intra-cytoplasmic tau-positive tangle-like inclusions were not detected in both type 1 and type 2 diabetes brains $[55,56]$, different tau phosphorylation sites were reported in the brains of DM patients. ClodfelderMiller et al. found a rapid and massive increase of tau phosphorylation at multiple residues including $\mathrm{Thr}$ 181, Ser 199, Ser 202, Thr 211, Thr 231, Ser 262, and Ser $396 / 404$ in the hippocampi of mice for 3 days after STZ treatment [56]. In another mouse study, the change of tau phosphorylations at AT8 (Ser 202 and Thr 205) and PHF-1 (Ser 396/404) epitopes in response to STZ treatment were found to be biphasic, a mild increased tau hyperphosphorylation was observed for 10,20 , and 30 days after STZ injection, and a massive tau hyperphosphorylation was detected after 40 days [53]. In our previous studies, tau hyperphosphorylated at Ser 199 / Thr 202 or Ser 396 site was detected in STZinduced diabetic mice after STZ-injection for 4 weeks or 45 days, respectively $[31,57]$. In the diabetic rats in the present study, in addition to the formation of tau hyperphosphorylated at both Thr 231 and PHF-1 epitopes in the hippocampi, the degree of tau hyperphosphorylation was positively correlated with that of plasma glucose levels and the degree of cognitive dysfunction.

Glucose concentrations larger than $25 \mathrm{mM}$ are considered as HGC that has been used to investigate the potential effects of hyperglycemia in neurons [58]. It was reported that primary hippocampal neuronsexposed for HGC (75 mM) for $24 \mathrm{~h}$ induces an increase in tau phosphorylation at Ser 199 [59]. It is believed that, compared withthe in vitro short-term (lesser than $24 \mathrm{~h}$ ) HGC exposure, the long-term (longer than $24 \mathrm{~h}$ ) HGC exposure is closer to in vivo chronic hyperglycemia [60]. Thus, the primary hippocampal neurons isolated from rat brains were exposed to $50 \mathrm{mM} \mathrm{HGC}$ for 6 days in the present study. We confirmed that long term HGC (50 $\mathrm{mM}$, for 6 days) significantly increases the levels of tau phosphorylation at both Thr231 and PHF-1 epitopesin primary neurons. Consistent to the results published in a previous study in primary neurons (long term HGC: $50 \mathrm{mM}$ for 7 days) [60], we found that at the similar experimental condition, the morphology and viability of primary neurons are hardly changed, although darkly stained cytoplasm and large cell body were observed in STZ-induced diabetic mice [57]. Probably, in vitro HGC exposure for 6 days is not long enough to cause significant cell death but enough to induce the formation of tau hyperphosphorylation. We speculated that inhibiting the formation of hyperphosphorylated tau at the early period of DM may prevent the development of a widespread neuronal degeneration. 


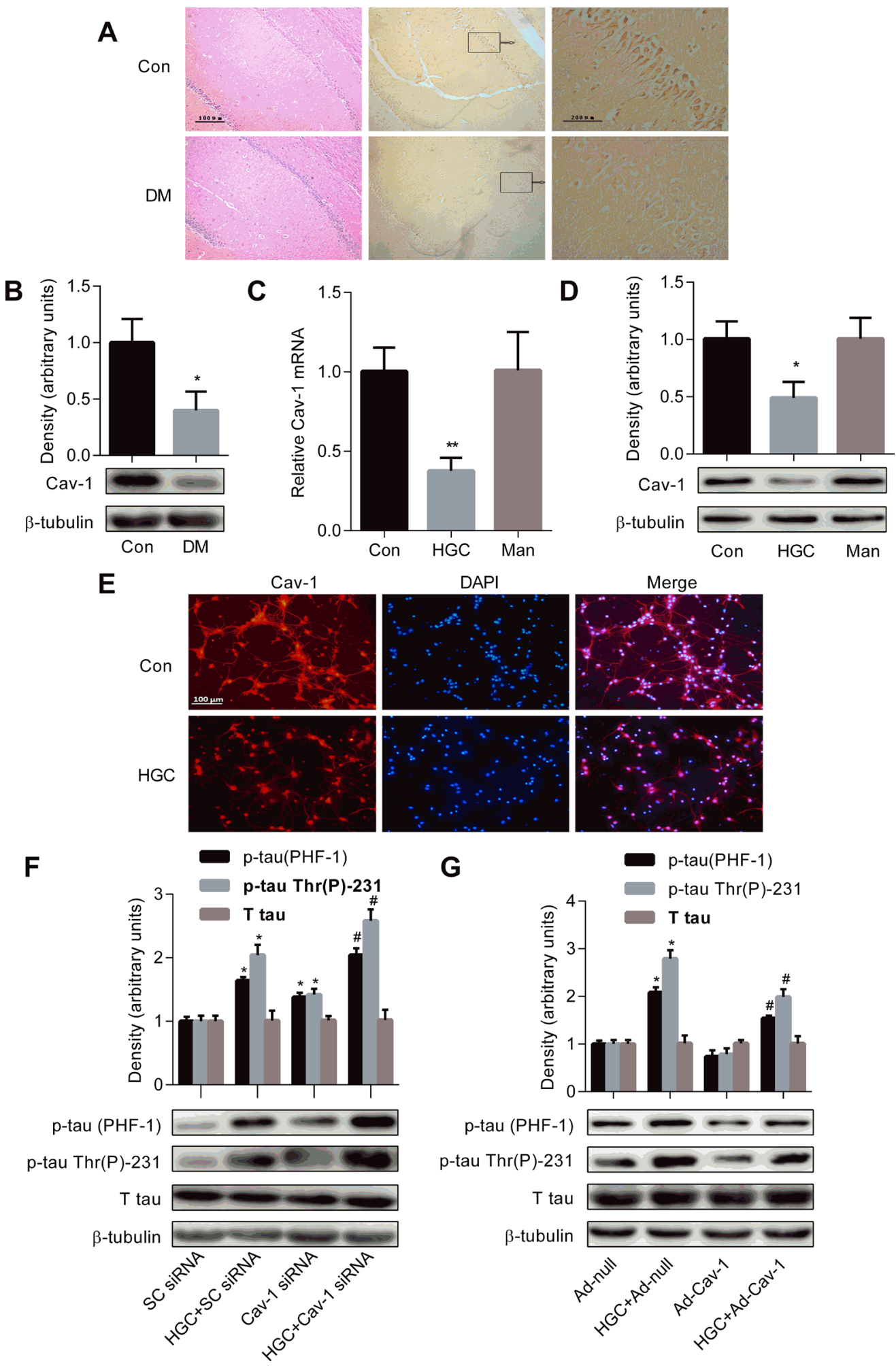

Figure 3: Decreased Cav-1 expression contributes to the formation of tau hyperphosphorylation under hyperglycemic condition. (A) Representative pictures from paraffin-embedded sections of control and diabetic rats immunostained with antibody to Cav-1. (B) Western blot showed the expression level of Cav-1 in the hippocampi of control and diabetic rats brains. Real time PCR (C) and Western blot (D) showed the expression level of Cav-1 in cultured hippocampal neurons exposed to $25 \mathrm{mM}$ glucose (Con), $50 \mathrm{mM}$ glucose (HGC) or $25 \mathrm{mM}$ mannitol (Man). ${ }^{*} p<0.05,{ }^{* *} p<0.01$ vs Con. (E) Immunofluorescence staining was used to detect the expression of Cav-1 in hippocampal neurons. Cav-1 was shown in red. (F) Knockdown of Cav-1 aggravates tau hyperphosphorylation after HGC. ${ }^{*} p<0.05$ vs SC-siRNA; ${ }^{p} p<0.05$ vs HGC+SC-siRNA. (G) Over-expression of Cav-1 ameliorates HGC-induced tau hyperphosphorylation. $* p<0.05$ vs Ad-null; $* p<0.05$ vs HGC + Ad-null. Error bars represent s.e.m. 
As mentioned above, mTOR signalling is required for the formation of tau hyperphosphorylation in several cellular and animal models such as human SH-SY5Y neuroblastoma cells and mouse neuroblastoma 2a (N2a) cells, primary cortical neurons, metabolically active brain slices, triple-transgenic model of $\mathrm{AD}(3 \mathrm{xTg}-\mathrm{AD})$ mice and tau P301S transgenic mice [22-27, 61, 62]. mTOR/S6K signalling could regulate glucose metabolism including inhibiting glucose uptake, improving glycogen synthesis and stimulating glycolysis [15-19], and a feedback regulation mechanism of $\mathrm{mTOR}$ by glucose metabolism is suggested by the findings that HGC activates mTOR signalling in rat PC12 pheochromocytoma cells (a clonal cell line closely related to sympathetic neurons) and HT22 cells (an immortalized mouse hippocampal cell line) [63, 64]. It was demonstrated that the chronic activation of mTOR by high glucose results in insulin resistance [65] and the hyperactivation of mTOR is involved in diabetic
A
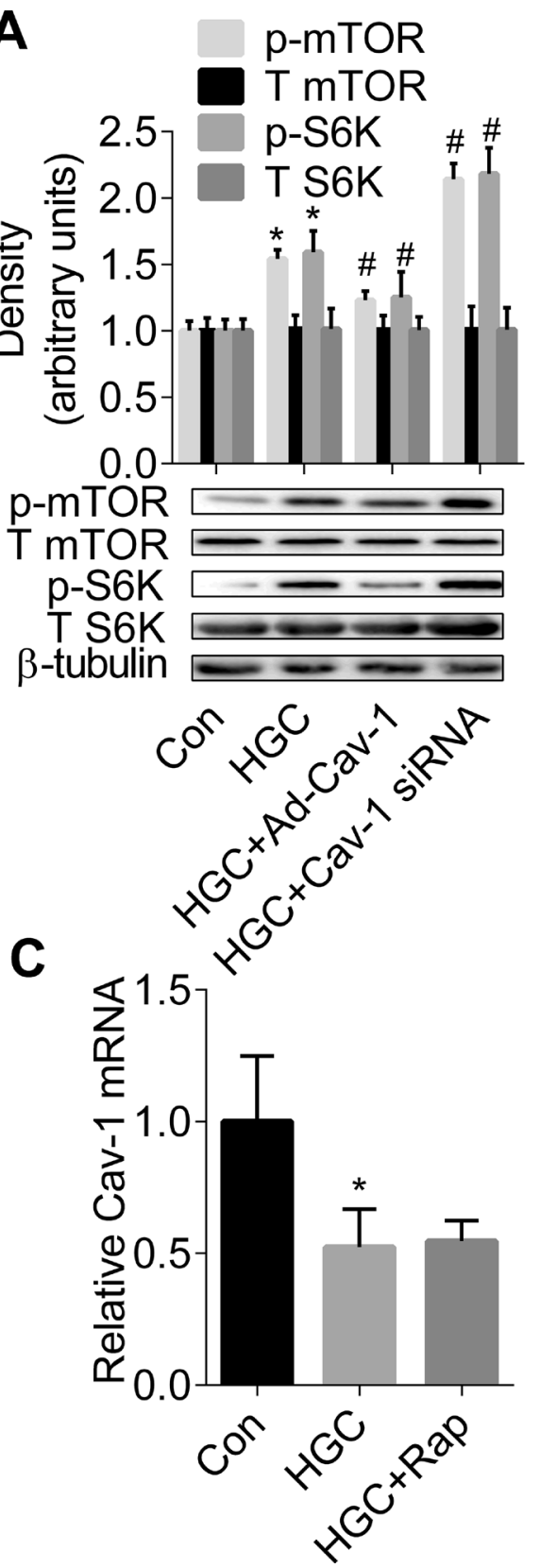

B

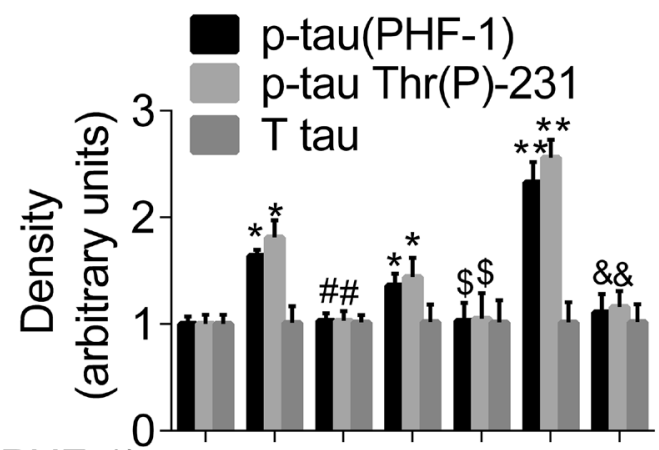

p-tau (PHF-1) p-tau $\operatorname{Thr}(\mathrm{P})-231 \rightleftharpoons-\ldots$

T tau $\beta$-tubulin

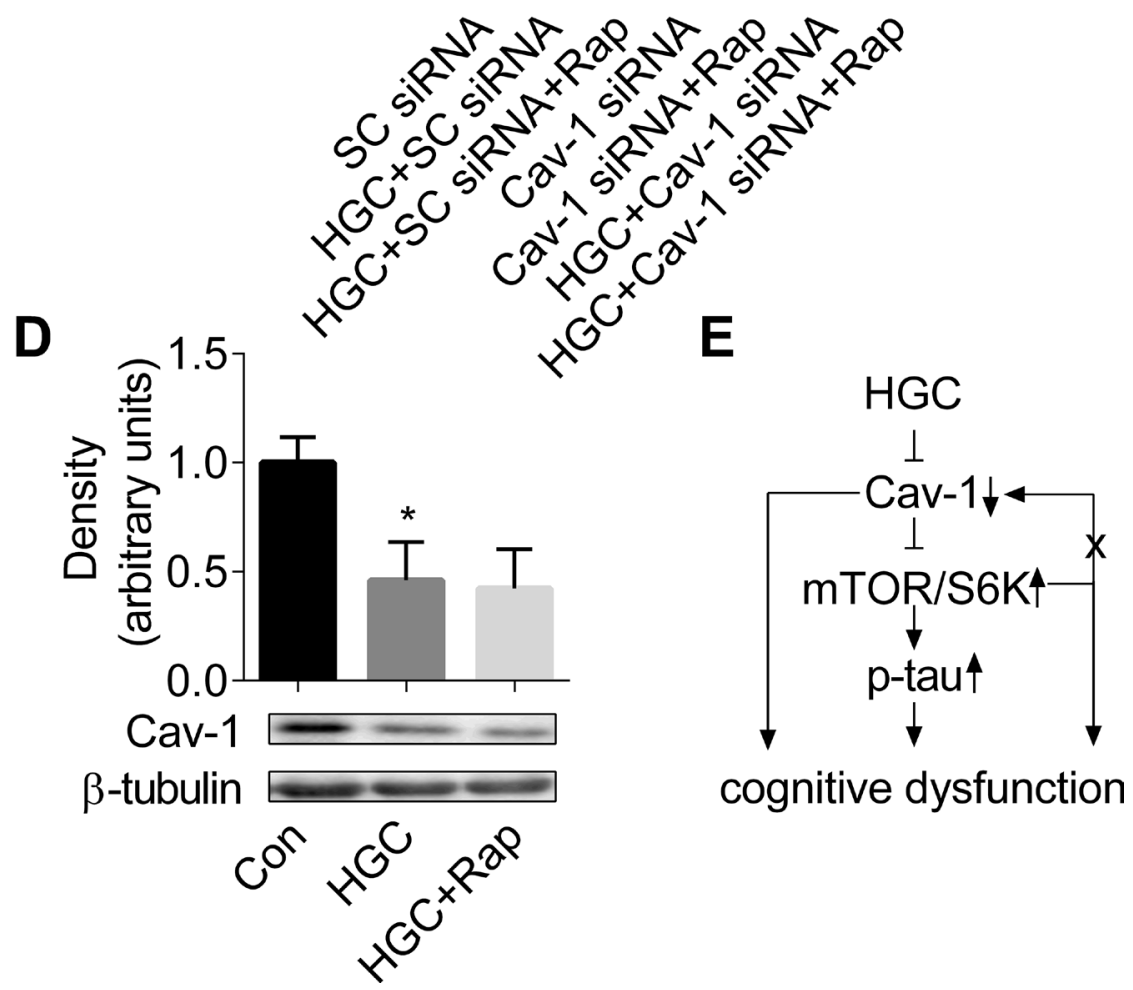

Figure 4: mTOR/S6K signalling is required for formation of Cav-1-regulated tau hyperphosphorylation. (A) Cav-1induced counteraction of HGC is associated with mTOR/p70S6K signalling in hippocampal neurons. ${ }^{*} p<0.05$ vs Con; ${ }^{*} p<0.05$ vs HGC. (B) $\mathrm{mTOR} / \mathrm{p} 70 \mathrm{~S} 6 \mathrm{~K}$ signalling is required for HGC and/or Cav-1 knockdown-induced tau hyperphosphorylation. * $p<0.05$ vs SC-siRNA; ${ }^{\#} p<0.05$ vs HGC + SC-siRNA; ${ }^{\$} p<0.05$ vs Cav-1 siRNA; ${ }^{\star} p<0.05$ vs HGC + Cav-1 siRNA. (C-D) The mRNA and protein expressions of Cav-1 were not regulated by mTOR signalling in hipocampal neurons. ${ }^{*} p<0.05$ vs Con. (E) a summary of the roles of Cav-1-mTOR/ S6K signalling and tau hyperphosphorylation in DM-mediated cognitive dysfunction. Error bars represent s.e.m. 
complications [66]. We found sharp increased levels of p-mTOR and p-S6K in the hippocampi of STZ-induced diabetic rats, the increases correlates with the levels of p-tau. Increased levels of p-mTOR, p-S6 (the substrate of $\mathrm{S} 6 \mathrm{~K})$ and p-tau were also reported in Zucker diabetic fatty rat brains [67]. Recently, we showed that pharmacological inhibition of the over-activated mTOR/S6K signalling with rapamycin rescues cognitive deficits and decreases tau hyperphosphorylation in STZ-induced mouse DM model [31].

The indispensable roles of Cav-1 on neuronal system have been demonstrated in different animal and cell models: improvement of learning and memory in neuron-targeted Cav-1 overexpression mice [34], enhanced brain lesion volume and neuroinflammation in Cav-1 deficient mice [68], accelerated neurodegeneration in Cav-1 knockout mice [35], and a progressive decrease in Cav-1 expression under HGC accelerated the neuregulin-induced degenerationin Schwann cells (SC)/ dorsal root ganglion (DRG) co-cultures [69]. Recently, enhanced hepatic gluconeogenesis and glucose output were observed in the Cav-1 null mice [70], and suppressed glycolysis was noted in Cav-1 reconstituted breast cancer epithelial cells [71], suggesting its implication in glucose metabolism. In addition to the evidence that Cav-1 expression is down-regulated by HGC in several cells [40-42, 69], Cav-1 function has also been investigated in diabetic nephropathy [72], diabetic retinopathy [73], and diabetic wound healing [74]. In the present study, a significant decrease of Cav-1 was found by Western blotting in the homogenates prepared from the hippocampi of diabetic rats, which is consistent with the results from the previous study [43]. A decreased Cav-1 immunoreactivity was consistently observed by immunohistochemistry in the hippocampal neurons in the brains of diabetic rats and by immunofluorescence in primary neurons in HGC group. Furthermore, we demonstrated that Cav-1 over-expression protects neurons from formation of tau hyperphosphorylation induced in HGC, whereas silencing Cav-1 expression aggravates the degree of tau hyperphosphorylation. Our results suggested that decreased Cav-1 expression contributes to the formation of tau hyperphosphorylation in HGC. However, an opposite report demonstrated that overexpression of Cav-1 increased ratio of tau-Ser 404/tau protein in N2a/ APP695swe cells, which stably expressing APP [75]. This discrepancy might be due to different cell types (primary hippocampal neurons or N2a cell lines) and experimental models (DM-related or AD-related cellular model).

A negative regulation of mTOR signalling by Cav-1 has been demonstrated in several cellular model systems: a remarkable increase of mTOR acitvity in Cav-1-deficient cancer-associated fibroblasts [36], hypoactivation of mTOR signalling in Cav-1-overexpressing U87MG cells $[37,38]$ inhibited the activation of $\mathrm{PI} 3 \mathrm{~K} / \mathrm{AKT} / \mathrm{mTOR}$ signalling in HL-60 cells with Cav-1 over-expression
[39]. In the present study, Cav-1 over-expression inhibited HGC-induced increased level of p-mTOR and p-S6K, whereas Cav-1 silencing aggravated the over-activated mTOR/S6K signalling. Our results for the first time in literatures indicated that Cav-1negatively regulates the activity of mTOR/S6K signalling pathway in neurons. However, we have also noticed that a positive correlation between Cav-1 and mTOR signalling is reported in literatures, such as a sustained activation of Cav-1 and $\mathrm{PI} 3 \mathrm{~K} / \mathrm{Akt} / \mathrm{mTOR}$ signalling cascades by low shear stress in breast carcinoma MDA-MB-231 cells [76], and galectin-1-induced p-mTOR inhibition by Cav-1 siRNA in mouse embryonic stem cells [77]. This discrepancy might be due to different cell types and different treatment factors. Our findings that the inhibition of mTOR with rapamycin attenuated Cav-1 deficiency-induced tau hyperphosphorylation suggest that Cav-1 negatively regulates tau phosphorylation via $\mathrm{mTOR} / \mathrm{S} 6 \mathrm{~K}$ signalling pathway. However, neither mRNA or protein expression of Cav-1 was affected by rapamycin treatment. These evidence suggest that a sustained over-activation of mTOR signalling induced by Cav-1 down-regulation can not form a negative feedback loop to reverse the abnormal expression of Cav-1.

In physiological condition, mTOR plays a role in memory processing [20]. Taken together, it suggests that the decline of cognitive function in DM is triggered by hyperglycemia, the process of cognitive dysfunction is contributed by suppressed Cav-1 expression, overactivated mTOR/S6K signalling, and/or the formation of tau hyperphosphorylation (panel Figure 4E). Although this mechanism is needed to be further confirmed in DM patients, the results available so far should encourage more studies to explore the protective effects of Cav1 in cognitive dysfunction. Our results at least suggest a potential pharmaceutical intervention approach in diabetes-induced cognitive dysfunction.

\section{MATERIALS AND METHODS}

\section{Antibodies and materials}

Antibodies used in the study include: rabbit monoclonal anti- $\beta$ III tubulin for Western blot analysis (Abcam; ab52901; 1/8,000); rabbit monoclonal anti-PHF1 (Abcam; ab184951; 1/5,000); rabbit monoclonal anti-tau (phospho T231) (Abcam; ab151559; 1/5,000); chickenantitau (Abcam; ab75714; 1/30000); rabbit monoclonal antimTOR (phospho S2448) (Abcam; ab109268; 1/5,000); rabbit anti-mTOR (Cell Signalling; 2983; 1/1,000); rabbit anti-Phospho-S6K (Thr421/Ser424) (Cell Signalling; 9204; 1/1,000); rabbit anti-S6K (Cell Signalling; 9202; 1/1,000); rabbit anti-Cav-1 for western blot analysis (Santa Cruz Biotechnology; sc-894; 1/500); rabbit antiCav-1 for immunohistochemical staining (Santa Cruz Biotechnology; sc-894; 1/100); rabbit anti-Cav-1 for 
immunofluorescence (Santa Cruz Biotechnology; sc894; 1/50); rabbit monoclonal anti-Synaptophysin (Syn) (Abcam; ab32127; 1/50); rabbit monoclonal anti- $\beta$ III tubulin for immunofluorescence (Abcam; ab52901; 1/100).

The adenoviral Cav-1 (Ad-Cav-1) and the empty adenovirus vector (Ad-null) were generously gifted from Dr. Duan-Fang Liao (Hunan University of Traditional Chinese Medicine, China).

\section{Characterization of STZ-induced diabetic rats}

Male Sprague-Dawley (SD) rats (weighing 190220g) were purchased from the Experimental Animal Center of Central South University, Hunan, China. All experimental procedures were conducted according to the strict guidelines of the Animal Welfare Committee of Central South University. STZ (60 mg/kg) was intraperitoneally injected into rats to induce HGC observed in DM patients as previously described [78]. The control groups were injected with an equivalent volume of citrate buffer. Fasting plasma glucose (FPG) level was measured by the glucose oxidase method (GOD-PAP; BoehringerMannheim). When the FPG level of rats is higher than $300 \mathrm{mg} / \mathrm{dl}(n=10) 3$ days after STZ injection, diabetes was diagnosed. Behavioral experiments were carried out and rats were sacrificed in the 12 th week. Since the hippocampus plays a central role in regulation of spatial learning and memory in rodents [79], hippocampal tissues in diabetic rats from hippocampi were selectively used to investigate the mechanism of cognitive impairment induced by hyperglycemia. Five rats each group were sacrificed and usedin immunohistochemistry and Western blot analyses.

\section{Cognitive measurement by Morris water maze test}

The abilities of spatial learning and memory were measured in diabetic and control rats by the Morris water maze test as previously described [80] prior to be sacrificed. A circular pool (250 cm in diameter) filled with water at $24^{\circ} \mathrm{C}-26^{\circ} \mathrm{C}$ was divided into four quadrants. For training, a submerged platform (15 $\mathrm{cm}$ in diameter) was fixed in the center of the fourth quadrant. Rat behaviors (latency, distance, swim speed, and navigation path) were recorded with a video camera connected to a computerized tracking system. The spatial learning ability was assessed by the escape time to reach the platform (escape latency). $24 \mathrm{~h}$ after testing trials, the ability of spatial memory was evaluated by the time spent in the target quadrant in which no platform was placed.

\section{HGC, infection, transfection, and rapamycin treatment in primary hippocampal neurons}

Primary hippocampal neurons were prepared as described by Wang et al. [81]. Briefly, after papain digestion, hippocampal neurons isolated from 18-dayold SD rat embryos were seeded on plates coated with $0.1 \mathrm{mg} / \mathrm{ml}$ poly-D-lysine in Dulbecco's Modified Eagle Medium/Nutrient Mixture F-12 (DMEM/F12) (Gibco Life Technologies, USA) containing $10 \%$ FBS in a $37^{\circ} \mathrm{C}$ humidified incubator with $5 \% \mathrm{CO}_{2}$ for $4 \mathrm{~h}$. The seeded hippocampal neurons were cultured with Neurobasal medium (Gibco Life Technologies, USA), supplemented with B27 (1:50 dilution; Gibco Life Technologies, USA). Half of the medium was replaced every 2-3 days. After 6 days, the experiments were carried out as following:

HGC

The primary neurons were incubated with $50 \mathrm{mM}$ glucose (HGC group) or $25 \mathrm{mM}$ mannitol (plus $25 \mathrm{mM}$ glucose in Neurobasal medium, control group), and maintained for another 6 days.

\section{Viral infection}

The primary neurons were infected by Ad-Cav-1 or Ad-null. To confirm the over-expression of Cav-1, the neurons were harvested at $24 \mathrm{~h}$ for RNA extraction and at $48 \mathrm{~h}$ for protein extraction after infection. After $48 \mathrm{~h}$ infection, the infected primary neurons were exposed to HGC for another 6 days in order to study the potential effect of Cav-1 over-expression on HGC-induced tau hyperphosphorylation.

\section{Transfection}

The primary neurons were transfected with Cav1 siRNA or scrambled control siRNA (SC-siRNA) (Invitrogen, USA) using Lipofectamine RNAi MAX (Invitrogen, USA) following the manufacturer's instructions. In order to confirm the silencing degree of Cav-1, the neurons were harvested at $24 \mathrm{~h}$ for RNA extraction and at $48 \mathrm{~h}$ for protein extraction after tranfection. After $48 \mathrm{~h}$ transfection, the transfected neurons were exposed to HGC for another 6 days for studying the potential effect of Cav-1 knockdown on HGC-induced tau hyperphosphorylation.

\section{Rapamycin treatment}

the transfected and non-transfected primary neurons were pretreated with rapamycin (200 nM; Sigma, USA) or DMSO for $2 \mathrm{~h}$ prior to the exposure of HGC for studying the potential role of mTOR signalling in HGC-inducedtau hyperphosphorylation.

\section{Neuronal viability assay}

The primary neurons were plated in 96 well plates and cultured for 6 days, and half of the medium was replaced every 2-3 days. After exposed to HGC for another 6 days, the neuronal viability was determined following the protocol provided for the Cell Counting Kit-8 (CCK-8) kit (Dojindo, Japan). Briefly, culture media were absorbed and replaced with $10 \%$ CCK-8in 
Neurobasal/B27 medium. After incubation at $37^{\circ} \mathrm{C}$ for $4 \mathrm{~h}$, absorbance was measured at the wavelength of $450 \mathrm{~nm}$ with $650 \mathrm{~nm}$ as reference.

\section{RNA extraction and RNA level determination}

After experiments, total RNA was isolated from primary hippocampal neurons using TRIzol reagent (Invitrogen, USA) as described previously [82]. The levels of mRNA for Cav- 1 and $\beta$-actin were analyzed by realtime quantitative RT-PCR using SYBR-Green dye and Applied Biosystems (GeneCopoeia, USA). The mRNA for Cav-1 was amplified and quantified with primers as listed below. The synthetic oligonucleotide primer sequences for $\mathrm{Cav}-1$ and $\beta$-actin were as follows: $\mathrm{Cav}-1$ 5'-TCTACAAGCCCAACAACAAGGCC-3' (upstream) and 5'-TGCACTGAATCTCAATCA-GGAAGC-3' (downstream); $\beta$-actin 5'-CAACGAGCGGTT- CCGAT3' (upstream) and 5'-GCCACAGGATTCCATACCCA$3^{\prime}$ (dowmstream). Amplification condition was set as follows: pre-denaturation at $95^{\circ} \mathrm{C}$ for $5 \mathrm{~min}, 40$ cycles of denaturation at $95^{\circ} \mathrm{C}$ for $10 \mathrm{~s}$, annealing at $60^{\circ} \mathrm{C}$ for $20 \mathrm{~s}$, extension at $72^{\circ} \mathrm{C}$ for $30 \mathrm{~s}$. Cav-1 mRNA levels were normalized to that of $\beta$-actin.

\section{Protein extraction, protein measurement and Western blot analysis}

After behavioral experiments were carried out, five rats each group were sacrificed under deep anesthesia with diethylether. Hippocampi were dissected from rat brains and homogenized in buffer containing $50 \mathrm{mM}$ Tris, pH 7.0, $2.5 \mathrm{mM}$ EDTA, $2.5 \mathrm{mM}$ EGTA, $2 \mathrm{mM}$ benzamidine, $0.5 \mathrm{mM}$ PMSF, $0.1 \% \beta$-mercaptoethanol, $20 \mathrm{mM} \beta$-glycerophosphate, $0.1 \%$ protease inhibit or cocktail (Sigma, USA), $2 \mathrm{mM}$ sodium vanadate, $50 \mathrm{mM}$ $\mathrm{NaF}$, and $2 \%$ SDS at $4{ }^{\circ} \mathrm{C}$ [83]. Protein concentration was detected with a bicin choninic acid (BCA) protein assay kit (Beyotime, China).

Primary neurons were harvested and lysed in iced lysis buffer containing $40 \mathrm{mM}$ HEPES, $120 \mathrm{mM}$ $\mathrm{NaCl}, 1 \mathrm{mM}$ EDTA, $10 \mathrm{mM}$ pyrophosphate, $10 \mathrm{mM}$ glycerophosphate, $50 \mathrm{mM} \mathrm{NaF}, 0.5 \mathrm{mM}$ or thovanadate, $1 \%$ Triton $\mathrm{X}-100$, and $1 \%$ protease inhibitor mixture [23]. The supernatant samples were obtained after centrifuging at $13,000 \times \mathrm{g}$ for $20 \mathrm{~min}$. Twenty microgram protein samples were loaded each lane. Protein samples were separated by SDS-polyacrylamide gels (SDS-PAGE) and transferred to nitrocellulose membrane. The membranes were blocked with 5\% non-fat milk prior to incubation with primary antibody. Membranes were washed with TBS-T (Tris-buffered saline supplemented with $0.1 \%$ Tween-20) and incubated with secondary antibodies (ZSGB-BIO, China). Relative density of each protein band was normalized to that of $\beta$-III tubulin. All results were representative of at least five independent experiments.

\section{Immunofluorescence and immunohistochemsitry}

The primary hippocampal neurons were plated on poly-1-lysine coated $22 \mathrm{~mm}$ diameter glass coverslips at a density of $2 \times 10^{5}$ cells per coverslip and cultured for 6 days, and half of the medium was replaced every 2-3 days. After the neurons were exposed to HGC for another 6 days, the coverslips were removed from the wells and placed in coverslip holders. Then the neurons were fixed with $4 \%$ paraformaldehyde and permeabilized with $0.1 \%$ Triton X-100.After $10 \mathrm{~min}$, the neurons were blocked with $1 \%$ bovine serum albumin (BSA) (Sigma, USA)at room temperature for $20 \mathrm{~min}$. After washing, the neurons were incubated with primary antibodies at $4^{\circ} \mathrm{C}$ overnight, followed by incubation with FITC-conjugated secondary antibodies. The slides were mounted and observed under fluorescence microscope (Leica, PA).

After behavioral experiments were carried out, five rats each group were sacrificed under deep anesthesia with diethyl ether and transcardially perfused with 4\% paraformaldehyde $\mathrm{pH} 7.4$, and whole brain was dissected and embedded in paraffin according to the method described in our previous publication [83]. The tissue blocks were sectioned in $6 \mu \mathrm{m}$ thickness. To eliminate non-specific binding, the sections were treated with 3\% normal goat serum at room temperature. The sections were then incubated with at primary antibodies at $4^{\circ} \mathrm{C}$ overnight, followed by incubation with biotinylated secondary antibody room temperature for 2 $\mathrm{h}$, and visualized using the avidin-biotin-peroxidase complex kit (ZSGB-BIO, China) with 3-3'-diaminobenzidine-4 HCl/ $\mathrm{H}_{2} \mathrm{O}_{2}$ (DAB; Sigma) as a substrate.

\section{Statistical analysis}

The data were expressed as the mean \pm s.e.m. For the comparison of means between two groups, student's $t$ test was used. For the comparison of means $\geq$ three groups, one-way ANOVA and the Tukey's test were used. $p \leq 0.05$ were considered statistically significant.

\section{ACKNOWLEDGMENTS}

We thank Yong-Zhen Gong and Shao-Wei Sun for their works in cell culture.

\section{CONFLICTS OF INTEREST}

The authors declare no conflicts of interest.

\section{GRANT SUPPORT}

This work was supported by the National Natural Science Foundation of China (No. 81170754, 81402915, 81470046, 81573480 and 81670771) and the Key Research and Development Program of Hunan Province (No.2016JC2071). 


\section{REFERENCES}

1. McCrimmon RJ, Ryan CM, Frier BM. Diabetes and cognitive dysfunction. Lancet. 2012; 379:2291-2299.

2. Wennberg AM, Gottesman RF, Kaufmann CN, Albert MS, Chen-Edinboro LP, Rebok GW, Kasper JD, Spira AP. Diabetes and cognitive outcomes in a nationally representative sample: the National Health and Aging Trends Study. Int Psychogeriatr. 2014; 26:1729-1735.

3. Formiga F, Ferrer A, Padros G, Corbella X, Cos L, Sinclair AJ, Rodriguez-Manas L. Diabetes mellitus as a risk factor for functional and cognitive decline in very old people: the Octabaix study. J Am Med Dir Assoc. 2014; 15:924-928.

4. Wang X, Zhao L. Calycosin ameliorates diabetes-induced cognitive impairments in rats by reducing oxidative stress via the PI3K/Akt/GSK-3beta signaling pathway. Biochem Biophys Res Commun. 2016; 473:428-434.

5. Weingarten MD, Lockwood AH, Hwo SY, Kirschner MW. A protein factor essential for microtubule assembly. Proc Natl Acad Sci USA. 1975; 72:1858-1862.

6. Kosik KS, Joachim CL, Selkoe DJ. Microtubule-associated protein tau (tau) is a major antigenic component of paired helical filaments in Alzheimer disease. Proc Natl Acad Sci USA. 1986; 83:4044-4048.

7. Arriagada PV, Growdon JH, Hedley-Whyte ET, Hyman BT. Neurofibrillary tangles but not senile plaques parallel duration and severity of Alzheimer's disease. Neurology. 1992; 42:631-639.

8. Platt TL, Beckett TL, Kohler K, Niedowicz DM, Murphy MP. Obesity, diabetes, and leptin resistance promote tau pathology in a mouse model of disease. Neuroscience. 2016; 315:162-174.

9. Jung HJ, Kim YJ, Eggert S, Chung KC, Choi KS, Park SA. Age-dependent increases in tau phosphorylation in the brains of type 2 diabetic rats correlate with a reduced expression of p62. Exp Neurol. 2013; 248:441-450.

10. Papon MA, El KN, Marcouiller F, Julien C, Morin F, Bretteville A, Petry FR, Gaudreau S, Amrani A, Mathews PM, Hebert SS, Planel E. Deregulation of protein phosphatase $2 \mathrm{~A}$ and hyperphosphorylation of tau protein following onset of diabetes in NOD mice. Diabetes. 2013; 62:609-617.

11. Alonso AD, Di Clerico J, Li B, Corbo CP, Alaniz ME, Grundke-Iqbal I, Iqbal K. Phosphorylation of tau at Thr212, Thr231, and Ser262 combined causes neurodegeneration. J Biol Chem. 2010; 285:30851-30860.

12. Di J, Cohen LS, Corbo CP, Phillips GR, El Idrissi A, Alonso AD. Abnormal tau induces cognitive impairment through two different mechanisms: synaptic dysfunction and neuronal loss. Sci Rep-Uk. 2016; 6:20833.

13. Qu ZS, Li L, Sun XJ, Zhao YW, Zhang J, Geng Z, Fu JL, Ren QG. Glycogen synthase kinase-3 regulates production of amyloid-beta peptides and tau phosphorylation in diabetic rat brain. ScientificWorldJournal. 2014; 2014:878123.
14. Biever A, Valjent E, Puighermanal E. Ribosomal Protein S6 Phosphorylation in the Nervous System: From Regulation to Function. Front Mol Neurosci. 2015; 8:75.

15. Yi H, Brooks ED, Thurberg BL, Fyfe JC, Kishnani PS, Sun B. Correction of glycogen storage disease type III with rapamycin in a canine model. J Mol Med (Berl). 2014; 92:641-650.

16. Duvel K, Yecies JL, Menon S, Raman P, Lipovsky AI, Souza AL, Triantafellow E, Ma Q, Gorski R, Cleaver S, Vander HM, MacKeigan JP, Finan PM, et al. Activation of a metabolic gene regulatory network downstream of mTOR complex 1. Mol Cell. 2010; 39:171-183.

17. Krebs M, Brunmair B, Brehm A, Artwohl M, Szendroedi J, Nowotny P, Roth E, Furnsinn C, Promintzer M, Anderwald C, Bischof M, Roden M. The Mammalian target of rapamycin pathway regulates nutrient-sensitive glucose uptake in man. Diabetes. 2007; 56:1600-1607.

18. Sipula IJ, Brown NF, Perdomo G. Rapamycin-mediated inhibition of mammalian target of rapamycin in skeletal muscle cells reduces glucose utilization and increases fatty acid oxidation. Metabolism. 2006; 55:1637-1644.

19. Varma S, Shrivastav A, Changela S, Khandelwal RL. Longterm effects of rapamycin treatment on insulin mediated phosphorylation of $\mathrm{Akt} / \mathrm{PKB}$ and glycogen synthase activity. Exp Cell Res. 2008; 314:1281-1291.

20. Lana D, Di Russo J, Mello T, Wenk GL, Giovannini MG. Rapamycin inhibits mTOR/p70S6K activation in CA3 region of the hippocampus of the rat and impairs long term memory. Neurobiol Learn Mem. 2017; 137:15-26.

21. Ljungberg MC, Bhattacharjee MB, Lu Y, Armstrong DL, Yoshor D, Swann JW, Sheldon M, D'Arcangelo G. Activation of mammalian target of rapamycin in cytomegalic neurons of human cortical dysplasia. Ann Neurol. 2006; 60:420-429.

22. Pei JJ, An WL, Zhou XW, Nishimura T, Norberg J, Benedikz E, Gotz J, Winblad B. P70 S6 kinase mediates tau phosphorylation and synthesis. Febs Lett. 2006; 580:107-114.

23. Tang Z, Bereczki E, Zhang H, Wang S, Li C, Ji X, Branca RM, Lehtio J, Guan Z, Filipcik P, Xu S, Winblad B, Pei JJ. Mammalian target of rapamycin (mTor) mediates tau protein dyshomeostasis: implication for Alzheimer disease. J Biol Chem. 2013; 288:15556-15570.

24. Tang Z, Ioja E, Bereczki E, Hultenby K, Li C, Guan Z, Winblad B, Pei JJ. mTor mediates tau localization and secretion: Implication for Alzheimer's disease. Biochim Biophys Acta. 2015; 1853:1646-1657.

25. Zhou XW, Tanila H, Pei JJ. Parallel increase in p70 kinase activation and tau phosphorylation (S262) with Abeta overproduction. Febs Lett. 2008; 582:159-164.

26. An WL, Cowburn RF, Li L, Braak H, Alafuzoff I, Iqbal K, Iqbal IG, Winblad B, Pei JJ. Up-regulation of phosphorylated/activated p70 S6 kinase and its relationship to neurofibrillary pathology in Alzheimer's disease. Am J Pathol. 2003; 163:591-607. 
27. Pei JJ, Gong CX, An WL, Winblad B, Cowburn RF, Grundke-Iqbal I, Iqbal K. Okadaic-acid-induced inhibition of protein phosphatase $2 \mathrm{~A}$ produces activation of mitogenactivated protein kinases ERK1/2, MEK1/2, and p70 S6, similar to that in Alzheimer's disease. Am J Pathol. 2003; 163:845-858.

28. Li X, Alafuzoff I, Soininen H, Winblad B, Pei JJ. Levels of mTOR and its downstream targets 4E-BP1, eEF2, and eEF2 kinase in relationships with tau in Alzheimer's disease brain. Febs J. 2005; 272:4211-4220.

29. Caccamo A, Majumder S, Richardson A, Strong R, Oddo S. Molecular interplay between mammalian target of rapamycin (mTOR), amyloid-beta, and Tau: effects on cognitive impairments. J Biol Chem. 2010; 285:13107-13120.

30. Kolosova NG, Vitovtov AO, Muraleva NA, Akulov AE, Stefanova NA, Blagosklonny MV. Rapamycin suppresses brain aging in senescence-accelerated OXYS rats. Aging (Albany NY). 2013; 5:474-484. doi: 10.18632/aging.100573.

31. Wang S, Zhou SL, Min FY, Ma JJ, Shi XJ, Bereczki E, $\mathrm{Wu}$ J. mTOR-mediated hyperphosphorylation of tau in the hippocampus is involved in cognitive deficits in streptozotocin-induced diabetic mice. Metab Brain Dis. 2014; 29:729-736.

32. Trushina E, Du Charme J, Parisi J, McMurray CT. Neurological abnormalities in caveolin-1 knock out mice. Behav Brain Res. 2006; 172:24-32.

33. Head BP, Hu Y, Finley JC, Saldana MD, Bonds JA, Miyanohara A, Niesman IR, Ali SS, Murray F, Insel PA, Roth DM, Patel HH, Patel PM. Neuron-targeted caveolin-1 protein enhances signaling and promotes arborization of primary neurons. J Biol Chem. 2011; 286:33310-33321.

34. Mandyam CD, Schilling JM, Cui W, Egawa J, Niesman IR, Kellerhals SE, Staples MC, Busija AR, Risbrough VB, Posadas E, Grogman GC, Chang JW, Roth DM, et al. Neuron-Targeted Caveolin-1 Improves Molecular Signaling, Plasticity, and Behavior Dependent on the Hippocampus in Adult and Aged Mice. Biol Psychiatry. 2017; 81:101-110.

35. Head BP, Peart JN, Panneerselvam M, Yokoyama T, Pearn ML, Niesman IR, Bonds JA, Schilling JM, Miyanohara A, Headrick J, Ali SS, Roth DM, Patel PM, et al. Loss of caveolin-1 accelerates neurodegeneration and aging. Plos One. 2010; 5:e15697.

36. Mercier I, Camacho J, Titchen K, Gonzales DM, Quann K, Bryant KG, Molchansky A, Milliman JN, WhitakerMenezes D, Sotgia F, Jasmin JF, Schwarting R, Pestell RG, et al. Caveolin-1 and accelerated host aging in the breast tumor microenvironment: chemoprevention with rapamycin, an mTOR inhibitor and anti-aging drug. Am J Pathol. 2012; 181:278-293.

37. Tanowitz HB, Machado FS, Avantaggiati ML, Albanese C. An expanded role for Caveolin-1 in brain tumors. Cell Cycle. 2013; 12:1485-1486.

38. Quann K, Gonzales DM, Mercier I, Wang C, Sotgia F, Pestell RG, Lisanti MP, Jasmin JF. Caveolin-1 is a negative regulator of tumor growth in glioblastoma and modulates chemosensitivity to temozolomide. Cell Cycle. 2013; 12:1510-1520.

39. Ma W, Wang DD, Li L, Feng YK, Gu HM, Zhu GM, Piao JH, Yang Y, Gao X, Zhang PX. Caveolin-1 plays a key role in the oleanolic acid-induced apoptosis of HL-60 cells. Oncol Rep. 2014; 32:293-301.

40. Carrillo-Sepulveda MA, Matsumoto T. Phenotypic modulation of mesenteric vascular smooth muscle cells from type 2 diabetic rats is associated with decreased caveolin-1 expression. Cell Physiol Biochem. 2014; 34:1497-1506.

41. Zhang Z, Yao K, Jin C. Apoptosis of lens epithelial cells induced by high concentration of glucose is associated with a decrease in caveolin-1 levels. Mol Vis. 2009; 15:2008-2017.

42. Hayashi T, Juliet PA, Miyazaki A, Ignarro LJ, Iguchi A. High glucose downregulates the number of caveolae in monocytes through oxidative stress from NADPH oxidase: implications for atherosclerosis. Biochim Biophys Acta. 2007; 1772:364-372.

43. Zhou H, Liu J, Ren L, Liu W, Xing Q, Men L, Song G, $\mathrm{Du}$ J. Relationship between [corrected] spatial memory in diabetic rats and protein kinase Cgamma, caveolin-1 in the hippocampus and neuroprotective effect of catalpol. Chin Med J (Engl). 2014; 127:916-923.

44. Arvanitakis Z, Wilson RS, Bienias JL, Evans DA, Bennett DA. Diabetes mellitus and risk of Alzheimer disease and decline in cognitive function. Arch Neurol. 2004; 61:661-666.

45. Elahi M, Hasan Z, Motoi Y, Matsumoto SE, Ishiguro K, Hattori N. Region-Specific Vulnerability to Oxidative Stress, Neuroinflammation, and Tau Hyperphosphorylation in Experimental Diabetes Mellitus Mice. J Alzheimers Dis. 2016; 51:1209-1224.

46. Kim DJ, Yu JH, Shin MS, Shin YW, Kim MS. Hyperglycemia Reduces Efficiency of Brain Networks in Subjects with Type 2 Diabetes. Plos One. 2016; 11:e157268.

47. Guo C, Zhang S, Li JY, Ding C, Yang ZH, Chai R, Wang X, Wang ZY. Chronic hyperglycemia induced via the heterozygous knockout of Pdx 1 worsens neuropathological lesion in an Alzheimer mouse model. Sci Rep. 2016; 6:29396

48. Xiang Q, Zhang J, Li CY, Wang Y, Zeng MJ, Cai ZX, Tian RB, Jia W, Li XH. Insulin resistance-induced hyperglycemia decreased the activation of Akt/CREB in hippocampus neurons: Molecular evidence for mechanism of diabetes-induced cognitive dysfunction. Neuropeptides. 2015; 54:9-15.

49. Jiang LY, Tang SS, Wang XY, Liu LP, Long Y, Hu M, Liao MX, Ding QL, Hu W, Li JC, Hong H. PPARgamma agonist pioglitazone reverses memory impairment and biochemical changes in a mouse model of type 2 diabetes mellitus. Cns Neurosci Ther. 2012; 18:659-666. 
50. Yang Y, Zhang J, Ma D, Zhang M, Hu S, Shao S, Gong CX. Subcutaneous administration of liraglutide ameliorates Alzheimer-associated tau hyperphosphorylation in rats with type 2 diabetes. J Alzheimers Dis. 2013; 37:637-648.

51. Rizzo MR, Barbieri M, Boccardi V, Angellotti E, Marfella R, Paolisso G. Dipeptidyl peptidase-4 inhibitors have protective effect on cognitive impairment in aged diabetic patients with mild cognitive impairment. J Gerontol A Biol Sci Med Sci. 2014; 69:1122-1131.

52. Zhou Y, Zhao Y, Xie H, Wang Y, Liu L, Yan X. Alteration in amyloid beta42, phosphorylated tau protein, interleukin 6 , and acetylcholine during diabetes-accelerated memory dysfunction in diabetic rats: correlation of amyloid beta42 with changes in glucose metabolism. Behav Brain Funct. 2015; 11:24.

53. Planel E, Tatebayashi Y, Miyasaka T, Liu L, Wang L, Herman M, Yu WH, Luchsinger JA, Wadzinski B, Duff KE, Takashima A. Insulin dysfunction induces in vivo tau hyperphosphorylation through distinct mechanisms. J Neurosci. 2007; 27:13635-13648.

54. Qu Z, Jiao Z, Sun X, Zhao Y, Ren J, Xu G. Effects of streptozotocin-induced diabetes on tau phosphorylation in the rat brain. Brain Res. 2011; 1383:300-306.

55. Li ZG, Zhang W, Sima AA. Alzheimer-like changes in rat models of spontaneous diabetes. Diabetes. 2007; 56:1817-1824.

56. Clodfelder-Miller BJ, Zmijewska AA, Johnson GV, Jope RS. Tau is hyperphosphorylated at multiple sites in mouse brain in vivo after streptozotocin-induced insulin deficiency. Diabetes. 2006; 55:3320-3325.

57. Zhao YM, Pei JJ, Ji ZJ, Zhao ZW, Qian YY, Sheng SL. Effect of amyloid precursor protein $17 \mathrm{mer}$ peptide on microtubule structure and tau protein hyperphosphorylation in hippocampal neurons of experimental diabetic mice. Neuroreport. 2003; 14:61-66.

58. Liu D, Zhang H, Gu W, Zhang M. Effects of exposure to high glucose on primary cultured hippocampal neurons: involvement of intracellular ROS accumulation. Neurol Sci. 2014; 35:831-837.

59. Chen Y, Cao CP, Li CR, Wang W, Zhang D, Han LL, Zhang XQ, Kim A, Kim S, Liu GL. Ghrelin modulates insulin sensitivity and tau phosphorylation in high glucoseinduced hippocampal neurons. Biol Pharm Bull. 2010; 33:1165-1169.

60. Gaspar JM, Castilho A, Baptista FI, Liberal J, Ambrosio AF. Long-term exposure to high glucose induces changes in the content and distribution of some exocytotic proteins in cultured hippocampal neurons. Neuroscience. 2010; 171:981-992.

61. Caccamo A, Magri A, Medina DX, Wisely EV, LopezAranda MF, Silva AJ, Oddo S. mTOR regulates tau phosphorylation and degradation: implications for Alzheimer's disease and other tauopathies. Aging Cell. $2013 ; 12: 370-380$.
62. Oddo S, Caccamo A, Shepherd JD, Murphy MP, Golde TE, Kayed R, Metherate R, Mattson MP, Akbari Y, LaFerla FM. Triple-transgenic model of Alzheimer's disease with plaques and tangles: intracellular Abeta and synaptic dysfunction. Neuron. 2003; 39:409-421.

63. Kumar P, Raman T, Swain MM, Mishra R, Pal A. Hyperglycemia-Induced Oxidative-Nitrosative Stress Induces Inflammation and Neurodegeneration via Augmented Tuberous Sclerosis Complex-2 (TSC-2) Activation in Neuronal Cells. Mol Neurobiol. 2017; 54:238-254.

64. Liu YW, Zhang L, Li Y, Cheng YQ, Zhu X, Zhang F, Yin $\mathrm{XX}$. Activation of mTOR signaling mediates the increased expression of AChE in high glucose condition: in vitro and in vivo evidences. Mol Neurobiol. 2016; 53:4972-4980.

65. Leontieva OV, Demidenko ZN, Blagosklonny MV. Rapamycin reverses insulin resistance (IR) in high-glucose medium without causing IR in normoglycemic medium. Cell Death Dis. 2014; 5:e1214.

66. Blagosklonny MV. TOR-centric view on insulin resistance and diabetic complications: perspective for endocrinologists and gerontologists. Cell Death Dis. 2013; 4:e964.

67. Talaei F, Van Praag VM, Shishavan MH, Landheer SW, Buikema H, Henning RH. Increased protein aggregation in Zucker diabetic fatty rat brain: identification of key mechanistic targets and the therapeutic application of hydrogen sulfide. Bmc Cell Biol. 2014; 15:1.

68. Niesman IR, Schilling JM, Shapiro LA, Kellerhals SE, Bonds JA, Kleschevnikov AM, Cui W, Voong A, Krajewski S, Ali SS, Roth DM, Patel HH, Patel PM, et al. Traumatic brain injury enhances neuroinflammation and lesion volume in caveolin deficient mice. J Neuroinflammation. 2014; 11:39.

69. Yu C, Rouen S, Dobrowsky RT. Hyperglycemia and downregulation of caveolin-1 enhance neuregulin-induced demyelination. Glia. 2008; 56:877-887.

70. Asterholm IW, Mundy DI, Weng J, Anderson RG, Scherer PE. Altered mitochondrial function and metabolic inflexibility associated with loss of caveolin-1. Cell Metab. 2012; 15:171-185.

71. Hart PC, Ratti BA, Mao M, Ansenberger-Fricano K, Shajahan-Haq AN, Tyner AL, Minshall RD, Bonini MG. Caveolin-1 regulates cancer cell metabolism via scavenging Nrf2 and suppressing MnSOD-driven glycolysis. Oncotarget. 2016; 7:308-322. doi: 10.18632/ oncotarget.5687.

72. Guan TH, Chen G, Gao B, Janssen MR, Uttarwar L, Ingram AJ, Krepinsky JC. Caveolin-1 deficiency protects against mesangial matrix expansion in a mouse model of type 1 diabetic nephropathy. Diabetologia. 2013; 56:2068-2077.

73. Klaassen I, Hughes JM, Vogels IM, Schalkwijk CG, Van Noorden CJ, Schlingemann RO. Altered expression of genes related to blood-retina barrier disruption in streptozotocininduced diabetes. Exp Eye Res. 2009; 89:4-15. 
74. Bitar MS, Abdel-Halim SM, Al-Mulla F. Caveolin-1/PTRF upregulation constitutes a mechanism for mediating p53induced cellular senescence: implications for evidencebased therapy of delayed wound healing in diabetes. Am J Physiol Endocrinol Metab. 2013; 305:E951-E963.

75. Kang Q, Xiang Y, Li D, Liang J, Zhang X, Zhou F, Qiao M, Nie Y, He Y, Cheng J, Dai Y, Li Y. MiR-124-3p attenuates hyperphosphorylation of tau protein-induced apoptosis via caveolin-1-PI3K/Akt/GSK3beta pathway in N2a/ APP695swe cells. Oncotarget. 2017; 8:24314-24326. doi: 10.18632/oncotarget.15149.

76. Yang H, Guan L, Li S, Jiang Y, Xiong N, Li L, Wu C, Zeng H, Liu Y. Mechanosensitive caveolin-1 activationinduced $\mathrm{PI} 3 \mathrm{~K} / \mathrm{Akt} / \mathrm{mTOR}$ signaling pathway promotes breast cancer motility, invadopodia formation and metastasis in vivo. Oncotarget. 2016; 7:16227-16247. doi: 10.18632/oncotarget.7583.

77. Lee MY, Lee SH, Park JH, Han HJ. Interaction of galectin-1 with caveolae induces mouse embryonic stem cell proliferation through the Src, ERas, Akt and mTOR signaling pathways. Cell Mol Life Sci. 2009; 66:1467-1478.

78. Rakieten N, Rakieten ML, Nadkarni MV. Studies on the diabetogenic action of streptozotocin (NSC-37917). Cancer Chemother Rep. 1963; 29:91-98.
79. Ergorul C, Eichenbaum H. The hippocampus and memory for "what," "where," and "when". Learn Mem. 2004; 11:397-405.

80. Vorhees CV, Williams MT. Morris water maze: procedures for assessing spatial and related forms of learning and memory. Nat Protoc. 2006; 1:848-858.

81. Wang YJ, Ren QG, Gong WG, Wu D, Tang X, Li XL, Wu FF, Bai F, Xu L, Zhang ZJ. Escitalopram attenuates beta-amyloid-induced tau hyperphosphorylation in primary hippocampal neurons through the 5-HT1A receptor mediated Akt/GSK-3beta pathway. Oncotarget. 2016; 7:13328-13339. doi: 10.18632/oncotarget.7798.

82. Wang S, Hu CP, Yuan Q, Zhang WF, Zhou Z, Nie SD, Jiang JL, Li YJ. Dimethylarginine dimethylaminohydrolase 1 regulates nerve growth factor-promoted differentiation of PC12 cells in a nitric oxide-dependent but asymmetric dimethylargenine-independent manner. J Neurosci Res. 2012; 90:1209-1217.

83. Wang S, Toth ME, Bereczki E, Santha M, Guan ZZ, Winblad B, Pei JJ. Interplay between glycogen synthase kinase-3beta and tau in the cerebellum of Hsp27 transgenic mouse. J Neurosci Res. 2011; 89:1267-1275. 